THERMAL COOK-OFF EXPERIMENTS OF THE HMX BASED HIGH EXPLOSIVE LX-04 TO CHARACTERIZE VIOLENCE WITH VARYING CONFINEMENT

F. Garcia, K. S. Vandersall, J. W. Forbes, C. M. Tarver, D. Greenwood

July 27,2005

American Physical Society Meeting on Shock Compression of Condensed Matter Baltimore, MD, United States July 31, 2005 through August 5, 2005 
This document was prepared as an account of work sponsored by an agency of the United States Government. Neither the United States Government nor the University of California nor any of their employees, makes any warranty, express or implied, or assumes any legal liability or responsibility for the accuracy, completeness, or usefulness of any information, apparatus, product, or process disclosed, or represents that its use would not infringe privately owned rights. Reference herein to any specific commercial product, process, or service by trade name, trademark, manufacturer, or otherwise, does not necessarily constitute or imply its endorsement, recommendation, or favoring by the United States Government or the University of California. The views and opinions of authors expressed herein do not necessarily state or reflect those of the United States Government or the University of California, and shall not be used for advertising or product endorsement purposes. 


\title{
THERMAL COOK-OFF EXPERIMENTS OF THE HMX BASED HIGH EXPLOSIVE LX-04 TO CHARACTERIZE VIOLENCE WITH VARYING CONFINEMENT
}

\author{
Frank Garcia ${ }^{1}$, Kevin S. Vandersall ${ }^{1}$, Jerry W. Forbes ${ }^{2}$, \\ Craig M. Tarver ${ }^{1}$, and Daniel Greenwood ${ }^{1}$
}

${ }^{1}$ Energetic Materials Center, Lawrence Livermore National Laboratory, Livermore, CA 94550

${ }^{2}$ Center for Energetic Concepts Development, University of Maryland, College Park, MD 20742

\begin{abstract}
Thermal cook-off experiments were carried out using LX-04 explosive (85\% HMX and $15 \%$ Viton by weight) with different levels of confinement to characterize the effect of confinement on the reaction violence. These experiments involved heating a porous LX-04 sample in a stainless steel container with varying container end plate thickness and assembly bolt diameter to control overall confinement. As expected, detonation did not occur and reducing the overall confinement lowered the reaction violence. This is consistent with modeling results that predict that a lower confinement will act to lower the cook-off pressure and thus the overall burn rate which lowers the overall violence. These results suggest that controlling the overall system confinement can modify the relative safety in a given scenario.
\end{abstract}

\section{INTRODUCTION}

Energetic materials can react violently when heated, resulting in a thermal explosion, or commonly called "cook-off." This situation generally poses two hazards, the initial thermal explosion event and any resulting fragments that may initiate a reaction in any adjacent energetic materials in close proximity. A better understanding is needed for safe handling, transportation, and storage of explosive devices. Experiments that measure the violence with energetic materials of known size, confinement, and heating rate are used to measure the relative safety of different scenarios and also calibrate computer models. These computer models can then be utilized to run a number of scenarios that are not as easily tested. In this work, the confinement of a previous experiment is reduced by two levels and tested to observe the effects of confinement changes and are referred to as the Thermal EXplosion Test (TEXT). These two additional experiments are compared with each other and the initial experiment.

Often times, thermal explosion events are generalized into "fast cook-off" or those occurring in minutes to a few hours and "slow cook-off" or those occurring over many hours or days. The experiments discussed here use a relatively quick heating rate of $\sim 5.7^{\circ} \mathrm{C} / \mathrm{min}$ until $170^{\circ} \mathrm{C}$, then $1^{\circ} \mathrm{C} / \mathrm{min}$ until explosion which means the experiment will take place over a few hours (i.e. "fast cook-off"). Comparing these tests to experiments with slow heating rates of $\sim 1^{\circ} \mathrm{C} /$ hour [1], which translates to experiments 
occurring over a few days can reveal different results. The combined results of these two extremes help understand the effect on heating rate. Modeling of these "fast" and "slow" cookoff examples will aid in understanding how heating rates affect the overall violence.

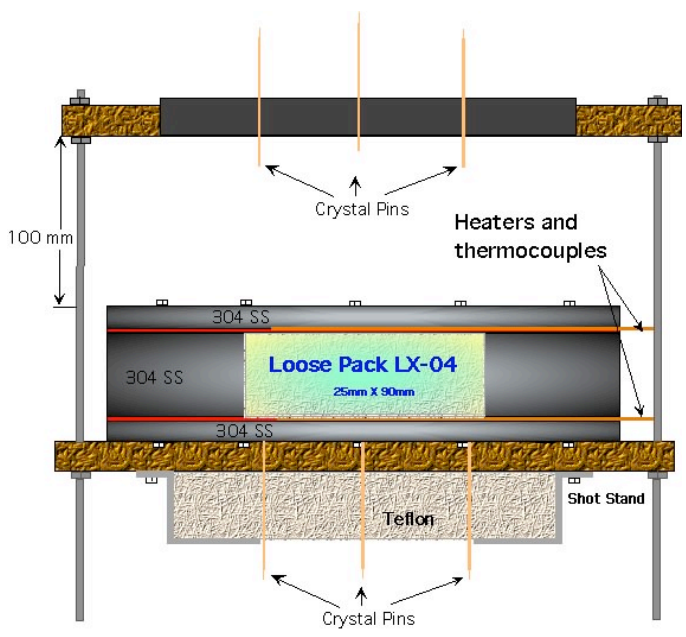

FIGURE 1. Diagram of the assembly for TEXT XI and TEXT XII experiments.

\section{EXPERIMENTAL PROCEDURE}

Two thermal explosion experiments were performed using LX-04 donor charges confined in 304 stainless steel cased donor assemblies with decreasing confinement from a prior test (TEXT X). These experiments, TEXT XI and XII used a porous LX-04 donor (55.6\% TMD) and a pin assembly at a $10 \mathrm{~cm}$ standoff. The experiment assembly for TEXT XI and XII is shown in Figure 1.

Heating of the donor occurred at a rate of $5.7^{\circ} \mathrm{C}$ a minute until the thermocouples located next to the nichrome heater foils recorded $170^{\circ} \mathrm{C}$ and soaked for about 30 minutes. Then the heating rate in the heater package was set at $1^{\circ} \mathrm{C} / \mathrm{min}$ until the explosive thermally reacted. Thermocouples were also placed on the case exterior to measure the thermal lag of temperatures from the heaters to the outer case.
The assembled experiments were placed inside a large steel expendable cylinder before firing to protect the firing chamber walls.

Several experiments have been previously performed with LX-04 explosives in this same series. Experiments TEXT VIII and TEXT IX [2] in addition to TEXT X [3] were detailed in prior publications and will not be fully described here, but will be referred to in the following sections for comparison and discussion. Extensive details about a prior series on PBX9501 are also indicated more specifically elsewhere [4].

\section{RESULTS/DISCUSSION}

The donor assembly in TEXT XI and XII cooked off as expected at a $232^{\circ} \mathrm{C}$ heater temperature $\left(216^{\circ} \mathrm{C}\right.$ exterior temperature) and $244^{\circ} \mathrm{C}$ heater temperature $\left(227^{\circ} \mathrm{C}\right.$ exterior temperature), respectively. The higher temperature recorded in TEXT XII is attributed to release of pressure in the donor as the thin cover plates buckled due to pressure buildup allowing gases to escape. The thermocouple outputs recorded for TEXT XII are included in Figure 2 for reference.

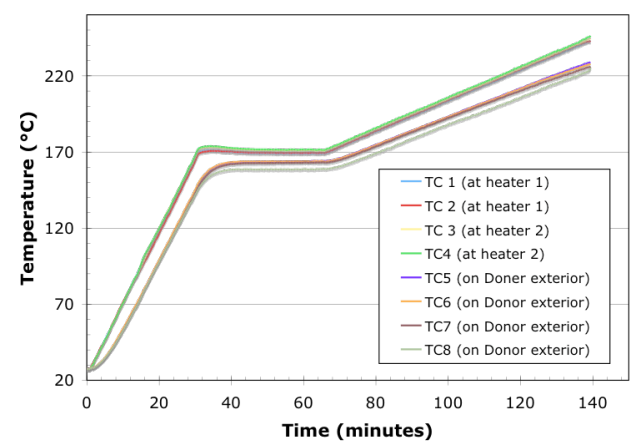

FIGURE 2. Thermocouple outputs recorded for experiment TEXT XII.

In TEXT XI, the cook-off was not violent enough to trigger the scopes from the pin signals so a velocity was not measured. In 
TEXT XII, the thin plates deformed instead of breaking the bolts and throwing a plate. The violence was found to decrease with decreasing confinement. The assembly hardware used and cook-off temperatures as discussed above are shown in Table I for reference. Prior TEXT experiments had $12 \mathrm{~mm}$ thick top and bottom plates with a $3 \mathrm{~mm}$ thick copper sealing plate attached by $9.5 \mathrm{~mm}$ diameter Grade 8 assembly bolts. The follow up tests used 6 and $3 \mathrm{~mm}$ thick plates with $1.5 \mathrm{~mm}$ thick copper sealing plates for TEXT XI and TEXT XII respectively, both with $6.4 \mathrm{~mm}$ diameter bolts.

TABLE I. Assembly bolt diameter, cover plate thickness, and temperatures near the heaters and on donor exterior for LX-04 TEXT experiments.

\begin{tabular}{||c|c|c|c||}
\hline \hline EXPT & $\begin{array}{c}\text { BOLT } \\
\text { DIA. }\end{array}$ & $\begin{array}{c}\text { COVER } \\
\text { THICKNESS }\end{array}$ & $\begin{array}{c}\text { TEMP. AT } \\
\text { COOKOFF }\end{array}$ \\
\hline TEXT X & $9.5 \mathrm{~mm}$ & $12 \mathrm{~mm}$ & $-/ 232^{\circ} \mathrm{C}$ \\
\hline TEXT XII & $6.4 \mathrm{~mm}$ & $6 \mathrm{~mm}$ & $216 / 232^{\circ} \mathrm{C}$ \\
\hline TEXT XII & $6.4 \mathrm{~mm}$ & $3 \mathrm{~mm}$ & $227 / 244^{\circ} \mathrm{C}$ \\
\hline
\end{tabular}

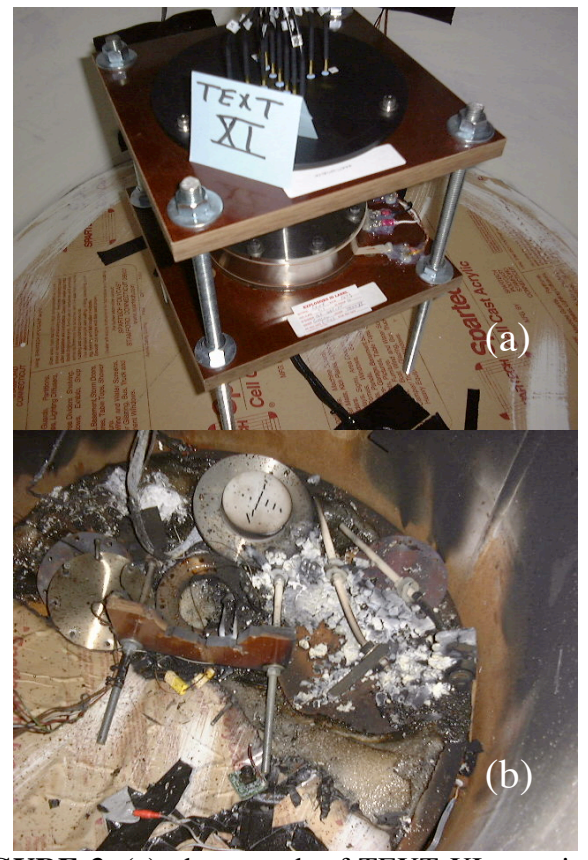

FIGURE 3. (a) photograph of TEXT XI experiment before and (b) after thermal explosion.

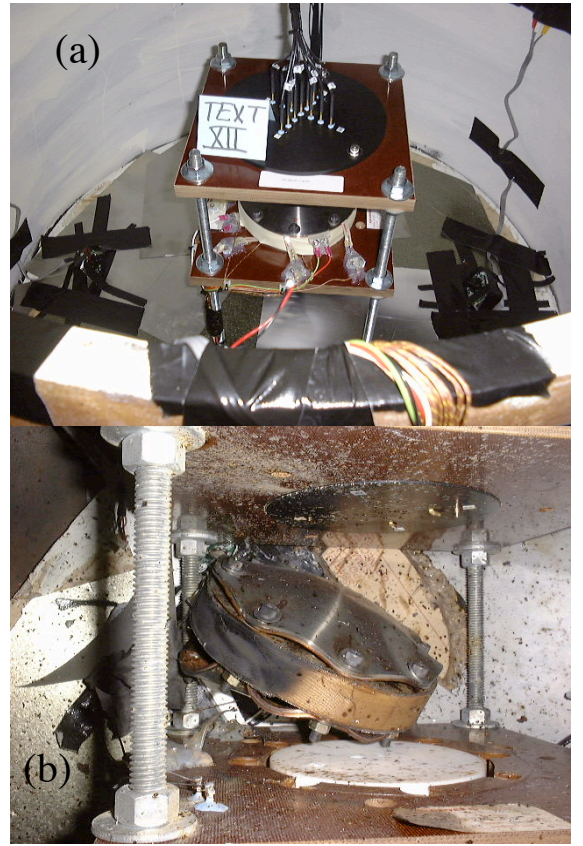

FIGURE 4. (a) photograph of TEXT XII experiment before and (b) after thermal explosion. Note the bulged cover plate and in tact bolts holding assembly together.

Photographs showing the before and after images of experiments TEXT XI and XII are shown in Figures 3 and 4 . The charring seen in Figure 3 (b) is the result of the acrylic base holding the experiment catching on fire shortly after the experiment which makes it look more violent than actuality. The fact that the plate impact did not trigger the adjacent pins below or the acceptor pin array $100 \mathrm{~mm}$ above, seems to reveal a rather low plate velocity and thus lower violence. This is backed up by the standard video (images not shown due to graininess) where the cook-off event could be discerned even at the low frame rate of approximately 1 frame per second. In TEXT XII, the reason for the pins not triggering is obvious due to the plates becoming bulged and venting highpressure gases and not resulting in a flying plate. 
These results are consistent with the previous LX-04 cook-off experiments. TEXT VIII had a full density donor during cook-off and did not have significant violence to even blow off the donor charge cover plates. This was the reason for going to the porous donor in TEXT IX, which sent a ramp wave into the Teflon acceptor in contact with donor top plate with peak pressures of $0.8 \mathrm{GPa}$ and a decaying ramp wave. The porosity plays an essential part in allowing the LX-04 to accumulate appreciable violence during thermal explosion.

In TEXT X, a porous LX-04 donor assembly was cooked off and the assembly plate was accelerated into a nearby heated $\left(100^{\circ} \mathrm{C}\right)$ acceptor at a $10 \mathrm{~cm}$ standoff with a final velocity of $350 \mathrm{~m} / \mathrm{s}$. The carbon resistor pressure gauge results (without temperature corrections) showed ramp waves with peak pressures of $0.7 \mathrm{GPa}$ and rise times of $\sim 2 \mu \mathrm{s}$. The ramp pressure wave decays very rapidly (i.e. does not build to detonation) as it moves through the acceptor charge and the rise times become more dispersed.

Modeling was performed in the prior TEXT experiments on the Donor cook-off and the modeling parameters were adjusted to obtain the correct measured Donor plate velocity. Because a measured plate velocity was not obtained in these experiments, this modeling was not performed. However, the modeling appears to agree with the result of a lower violence because it predicted that a slower burn rate would result in a lower pressure inside the Donor, and thus a lower overall violence (i.e. lower plate velocity).

\section{SUMMARY}

Two experiments, TEXT XI and XII, involving cook-off of a confined porous LX-04 explosive were performed with decreasing confinement from a prior test (TEXT X). In TEXT XI, the cook-off was not violent enough to trigger the scopes from the pin signals so a velocity was not measured. In TEXT XII, the thin plates deformed instead of breaking the bolts and throwing a plate. These results showed that the violence was found to decrease with decreasing confinement. The prior modeling performed agrees with this result since it predicted that with lower confinement, the burn rate observed and thus pressure pushing the donor confinement plates is less resulting in a reduced violence.

\section{ACKNOWLEDGEMENTS}

Jerry Dow at LLNL is generously thanked for funding this work. Assistance by Rich Villafana, Steve Kenitzer, and Gary Steinhour is gratefully acknowledged. This work was performed under the auspices of the U. S. Department of Energy by the University of California, Lawrence Livermore National Laboratory under Contract No. W-7405-Eng48.

\section{REFERENCES}

1. Wardell, J. F. and Maienschein, J. L., Proceedings of the 12th International Detonation Symposium, San Diego, CA, August, 2002, pp. 384-393.

2. Jerry W. Forbes, Frank Garcia, Craig M. Tarver, Paul A. Urtiew, Daniel W. Greenwood, and Kevin S. Vandersall, Proceedings of the 12th International Detonation Symposium, San Diego, CA, August, 2002, in press.

3. Frank Garcia, Kevin Vandersall, Jerry Forbes, Craig Tarver, Daniel Greenwood, "Pressure Wave Measurements Resulting From Thermal Cook-off of the HMX Based High Explosive LX04," Shock Compression of Condensed Matter2003, edited by M.D. Furnish, Y.M. Gupta, and J.W. Forbes, pp. 947-950, 2004.

4. Garcia, F., Forbes, J. W., Tarver, C. M., Urtiew, P. A., Greenwood, D. W., and Vandersall, K. S., Shock Compression of Condensed Matter-2001, Furnish, M. D., Thadhani, N. N., and Horie, Y, eds. CP-620, AIP Press, New York, 2002, p. 882. 